\title{
Automated classification of the atmospheric circulation patterns that drive regional wave climates
}

\author{
J. Pringle ${ }^{1}$, D. D. Stretch ${ }^{1}$, and A. Bárdossy ${ }^{1,2}$ \\ ${ }^{1}$ Centre for Research in Environmental, Coastal \& Hydrological Engineering, School of Engineering, \\ University of KwaZulu-Natal, 4041 Durban, South Africa \\ ${ }^{2}$ Institute of Hydraulic Engineering, Universität Stuttgart, 70569 Stuttgart, Germany \\ Correspondence to: D. D. Stretch (stretchd@ukzn.ac.za) \\ Received: 17 November 2013 - Published in Nat. Hazards Earth Syst. Sci. Discuss.: 5 February 2014 \\ Revised: 16 June 2014 - Accepted: 16 July 2014 - Published: 22 August 2014
}

\begin{abstract}
Wave climates are fundamental drivers of coastal vulnerability; changing trends in wave heights, periods and directions can severely impact a coastline. In a diverse storm environment, the changes in these parameters are difficult to detect and quantify. Since wave climates are linked to atmospheric circulation patterns, an automated and objective classification scheme was developed to explore links between synoptic-scale circulation patterns and wave climate variables, specifically wave heights. The algorithm uses a set of objective functions based on wave heights to guide the classification and find atmospheric classes with strong links to wave behaviour. Spatially distributed fuzzy numbers define the classes and are used to detect locally high- and lowpressure anomalies. Classes are derived through a process of simulated annealing. The optimized classification focuses on extreme wave events. The east coast of South Africa was used as a case study. The results show that three dominant patterns drive extreme wave events. The circulation patterns exhibit some seasonality with one pattern present throughout the year. Some $50-80 \%$ of the extreme wave events are explained by these three patterns. It is evident that strong lowpressure anomalies east of the country drive a wind towards the KwaZulu-Natal coastline which results in extreme wave conditions. We conclude that the methodology can be used to link circulation patterns to wave heights within a diverse storm environment. The circulation patterns agree with qualitative observations of wave climate drivers. There are applications to the assessment of coastal vulnerability and the management of coastlines worldwide.
\end{abstract}

\section{Introduction}

Wave climates are strongly linked to atmospheric circulation. The link is complex and its direct functional description can be difficult to derive. However atmospheric circulation can be classified into discrete patterns (CPs), which represent different links to wave behaviour. If these links can be clarified, they can be used to assess changes in the wave climate.

Understanding the wave climate at a given region is of fundamental importance to coastal planners, managers and engineers. Coastal erosion depends strongly on the extreme wave events, which in turn are driven by atmospheric circulation. Therefore changes in circulation patterns can change wave climate parameters (wave height, direction etc.). This has a direct impact on the location and severity of beach erosion. Wave climates along coastlines dominated by a single storm system are easiest to define, and changes in circulation patterns are reflected in wave observations. For example, Komar et al. (2010) were able to evaluate changes in the wave climate of the North Pacific and North Atlantic oceans. The shorelines along these coasts are typically dominated by one or two main storm systems with inherent seasonality. However in a diverse storm environment the trends can be more difficult to identify and quantify.

The aim of this study is to utilize existing statistical methods to identify the atmospheric circulation patterns driving the wave climate at a given location, with particular reference to extreme wave events. These events are defined here as periods during which significant wave heights exceed a threshold of $3.5 \mathrm{~m}$. Physical links between atmospheric features and wave heights are complex and nonlinear. Therefore 
attempts to model wave characteristics derived from circulation patterns can be difficult and time-consuming. Statistical knowledge gained from the observations of wave climates and pressure fields allows insight into this complex relationship without the need for explicit physical coupling. This can be a useful tool for risk analysis since it provides insight into the source of extreme events. If we understand the circulation patterns that drive extreme events, then their occurrence (or the occurrence of similar patterns) can have a degree of risk attached to it. For example the risk could be the likelihood of an extreme wave event, of severe erosion, of extended storm durations, or a combination of all three.

Circulation patterns are herein described in terms of pressure anomalies on the $700 \mathrm{hPa}$ geopotential. The types/classes or groups of anomalies can be specified by two approaches: (1) those specified prior to classification and (2) those that are derived and evolve during the classification process (Huth et al., 2008). In the past, anomaly patterns were identified by experts in the field: examples are the Hess-Brezowsky catalogue or the Lamb classification (Lamb, 1972; Hess and Brezowsky, 1952; Huth et al., 2008). However the power of modern computers provides a means to generate numerical solutions to complicated algorithms that can automate the process.

It is important to note that atmospheric circulation patterns are not a set of separated, well-defined states. CPs change smoothly between states that form part of a continuous sequence of events (Huth et al., 2008). Therefore the classes (or types) merely represent simplified climatic events responsible for specific variables of interest. While automated derivations of classification types utilize objective reasoning, according to Huth et al. (2008) the procedure as a whole cannot be considered fully objective. A number of subjective decisions are still employed. For example the number of CPs to use and the method of differentiating classes. Existing objective-based classification algorithms such as self-organizing maps (SOMs), principle component analysis (PCA) and cluster analysis provide effective ways to visualize the complex distribution of synoptic states (Huth et al., 2008; Hewitson and Crane, 2002). These approaches are fundamentally based on only the predictor variables (atmospheric pressure anomalies in our case). Links to surface weather variables are only made once the classification technique has been carried out. This can therefore lead to non-optimal links to the variable of interest (Bárdossy, 2010).

The classification method used for this study is a fuzzyrule-based algorithm developed by Bárdossy et al. (1995). The classification technique aims to find strong links between atmospheric CPs and a variable of interest, for this study the wave height. The algorithm was originally used to link atmospheric CPs with rainfall events (Bárdossy et al., 2002). In the present study the method has been adapted to use wave heights to guide the classification procedure. The main aim of this paper is to investigate the feasibility of using this method

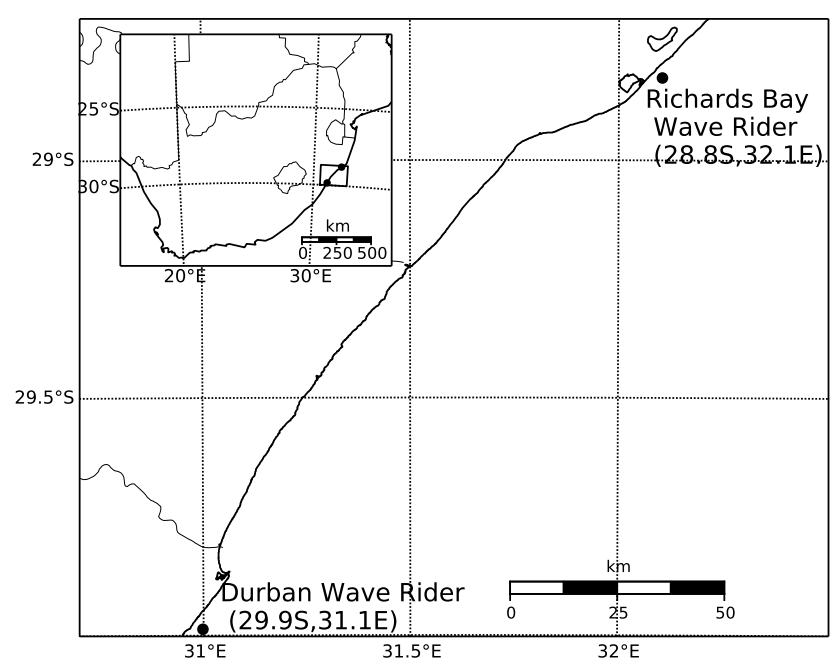

Figure 1. Locations of the wave observation buoys at Durban and Richards Bay, along the KwaZulu-Natal coastline.

to identify CPs that are the main drivers of regional wave climates for application to coastal vulnerability assessments.

\section{Methods}

\subsection{Case study site}

The KwaZulu-Natal (KZN) coastline (Fig. 1) has a highenergy wave climate. Tropical cyclones, mid-latitude (extratropical) cyclones and cut-off lows have been cited as important drivers of the local wave climate (Mather and Stretch, 2012; Corbella and Stretch, 2012b; Rossouw et al., 2011). Tropical cyclones that become stationary to the south east of Madagascar can occasionally drive large wave events that cause severe beach erosion in KZN (Mather and Stretch, 2012; Corbella and Stretch, 2012b). Cut-off lows are deep low-pressure systems that are displaced from the normal path of west-east moving mid-latitude cyclones (PrestonWhyte and Tyson, 1988). Instabilities within the westerly zonal flow, due to the high wind shear, create vortices (and low pressures) that can become cut-off and move equatorward (Preston-Whyte and Tyson, 1988). This diverse storm environment leads to seasonality within the wave climate. On average autumn and winter are associated with the largest wave energy, while summer has the smallest (Corbella and Stretch, 2012b). Seasons are defined according to Table 1.

\subsection{Sources of data}

Wave data were obtained from wave measurement buoys at two locations along the KwaZulu-Natal coastline (Fig. 1) for the period 1992-2009. A comparison of the wave data from the Durban and Richards Bay measurement locations by Corbella and Stretch (2012b) showed a strong correlation. 
Table 1. The allocation of months to seasons.

\begin{tabular}{ll}
\hline Season & Months \\
\hline Summer & January-March \\
Autumn & April-June \\
Winter & July-September \\
Spring & October-December \\
\hline
\end{tabular}

Therefore, where necessary, the two data sets were used to fill in missing data to provide a continuous wave record for the KwaZulu-Natal coastline. The data comprised significant wave heights, maximum wave heights, wave periods, and wave directions at 3-hourly intervals. However only daily values of significant wave heights were used for the analysis reported here.

The CP classification procedure was applied to daily normalized pressure anomalies that describe atmospheric circulation patterns. The anomalies were derived from the $700 \mathrm{hpa}$ geopotential height with a grid resolution of $2.5^{\circ}\left(10^{\circ} \mathrm{S}\right.$, $\left.0^{\circ} \mathrm{E}-50^{\circ} \mathrm{S}, 50^{\circ} \mathrm{E}\right)$. Geopotential heights were obtained from the ERA-Interim data set for the period 1979-2009 (http: //apps.ecmwf.int/datasets/). Letting $k(i, t)$ be the geopotential height at location $i$ and time $t$, then the anomaly at location $i$ and time $t$ is defined as

$h(i, t)=\frac{k(i, t)-\overline{k(i)}}{\sigma(i)}$,

where $\overline{k(i)}$ and $\sigma(i)$ are the average and standard deviation of the geopotential at location $i$.

\subsection{Classification methods}

The classification used herein comprises two parts: (1) an optimization procedure in which a set of classes defining atmospheric states are derived using an optimization process as described in Sect. 2.4, and (2) a classification method that involves a process of assigning CPs to the classes.

The aim is to identify a classification in which the set of classes defining atmospheric pressure fields can explain the occurrence of wave events at a specified location. There are many ways in which classification algorithms can be constructed. Classifications can be subjective, objective or a mixture of both (Bárdossy, 2010; Huth et al., 2008). Objective classification algorithms employ a self-learning technique whereby atmospheric classes are derived through an optimization procedure (for examples see Bárdossy, 2010; Bárdossy et al., 2002; Huth et al., 2008; Hewitson and Crane, 2002). Since the goal is to gain insight into the drivers of a regional wave climate, it follows that the wave climate should be included within the optimization procedure (see Sect. 2.4). Then the set of CP classes that are derived have strong links to the regional wave climate. Furthermore, classes linked with these variables explain, as best possible, their occurrences. This is a useful tool in guiding the algorithm to an optimal solution. Classifying CPs linked to extreme wave events is the focus of this study. The classifying procedure uses wave heights as the dependent variable to find classes of the independent variable, atmospheric pressure anomalies. The method of classification is described in detail by Bárdossy et al. (1995); Bárdossy et al. (2002) and Bárdossy (2010). Only a brief overview is given here.

The classification method used herein is fuzzy-rule-based which incorporates the use of fuzzy sets (Zadeh, 1965). This allows the algorithm to handle imprecise statements such as "strong high pressure" or "low pressure" (Bárdossy et al., 1995). The CPs at each time realization are assigned to a certain CP class or group. Each CP class is defined by a rule which comprises a number of fuzzy set membership functions. The $n$th CP class is described by the fuzzy rule $n$ as a vector $\boldsymbol{c}_{n}=[V(1, n), \ldots, V(i, n), \ldots, V(K, n)]$, for all available grid points $(1, \ldots, K)$, where $\mathbf{V}$ is the matrix containing all CP rules and the index $V(i, n)$ is the fuzzy set number corresponding to the location $i$ for rule $n$. The rules consist of the following fuzzy sets:

1. fuzzy set number 0 - any type of anomaly,

2. fuzzy set number 1 - strong positive anomaly,

3. fuzzy set number 2 - weak positive anomaly,

4. fuzzy set number 3 - weak negative anomaly and

5. fuzzy set number 4 - strong negative anomaly.

The fuzzy set numbers $(1, \ldots, 4)$ describe the locations of different pressure types. However, the fuzzy set number 0 is irrelevant for the $\mathrm{CP}$ classification. In general most of the grid points belong to this fuzzy set number. The algorithm only considers patterns with structures corresponding to the arrangement of the fuzzy set numbers $1, \ldots, 4$.

From the fuzzy set numbers described above, a membership grade $\mu$ at location $i$ can be assigned for each daily anomaly pattern as

$\mu_{n, j}(i, t)=g\left(c_{n}(i), t\right)$,

where $n$ is the fuzzy rule, $g\left(c_{n}(i), t\right)$ is the membership function for the fuzzy set number $j$ at location $i$ at time $t$ (Bárdossy et al., 2002). The membership grade $\mu$ at each location ranges between 0 and 1 based on the membership function for the location specific fuzzy number. A value of 0 implies that the anomaly value has no association with the fuzzy number, and a value of 1 implies the anomaly is strongly associated with the fuzzy number. It follows that a combination of the membership grades provide insight into the performance of each $\mathrm{CP}$ rule in relation to the daily anomaly patterns. A degree of fit (DOF) is computed for each $\mathrm{CP}$ rule, and the rule with the highest DOF value is assigned to the circulation pattern class for that day. The degree of fit is defined as follows (Bárdossy et al., 1995; Bárdossy et al., 2002): 
$\operatorname{DOF}(n, t)=\prod_{j=1}^{4}\left[\frac{1}{N(n, j)} \sum_{i=1}^{N(n, j)} \mu_{n, j}(i, t)^{P_{j}}\right]^{\frac{1}{P_{j}}}$,

where $t$ is the day, $N(n, j)$ is the number of grid points corresponding to the fuzzy set number $j$ for fuzzy rule $n$, the term $\sum_{i=1}^{N(n, j)} \mu_{n, j}(i, t)$ sums all the membership grades at various locations corresponding to the fuzzy set number $j$ for rule $n$, and the exponent $P_{j}$ is a parameter that allows us to emphasize the influence of selected rules on the DOF.

The $\mathrm{CP}$ rules were obtained via an optimization procedure following Bárdossy et al. (2002), which is described in Sect. 2.4.

\subsection{Optimization methods}

The goal of the optimization is to derive a set of CP classes or rules defining dominant circulation patterns in a particular region. The rules are strongly linked to a variable of interest. The optimization procedure should maximize dissimilarity between the $\mathrm{CP}$ types while minimizing the variability within the classes. The significant wave height $\left(H_{\mathrm{S}}\right)$ was selected as the variable of interest for this study. The algorithm considers both the daily average significant wave height and the daily maximum significant wave height. The optimization procedure was carried out for the period containing all wave data (1992-2009). A simulated annealing algorithm following Aarts and Korst (1989) is used in the optimization procedure. Details of the process are given in Bárdossy et al. (2002). The algorithm may be briefly outlined as follows:

1. Randomly assigned CP rules are initialized and their performance is evaluated through an objective function $O$.

2. The initial "annealing temperature" is set to $q_{0}$.

3. A rule $n$ is selected randomly.

4. A location $i$ is selected randomly.

5. A fuzzy number $c^{*}$ is selected randomly.

6. If $c_{n}(i)=c^{*}$, return to step 2 .

7. Set $c_{n}(i)=c^{*}$ and run the classification.

8. Calculate the new performance $O^{*}$ for the new rules.

9. If $O^{*}>O$, accept the change.

10. If $O^{*} \leq O$, accept the change with probability $\exp \left(\frac{O-O^{*}}{q_{j}}\right)$.

11. If the change has been accepted, replace $O$ by $O^{*}$.

12. Repeat steps $2-10$ a specified number of iterations.
13. Decrease the "annealing temperature" such that $q_{\text {new }}<q_{\text {old }}$.

14. Repeat steps 2-12, until the number of accepted changes becomes less than a predefined limit.

The optimization process relies strongly upon a set of objective functions. The objective functions are based on the extreme wave events, wave heights and storm duration as discussed below.

\section{Objective functions}

A good classification contains classes with corresponding wave statistics which differ from the statistics calculated without classification. The goal of the classification is to obtain a set of CP rules which correspond to the occurrence of extreme waves. Extreme waves events are defined where $H_{\mathrm{s}} \geq 3.5 \mathrm{~m}$. Therefore the objective functions used within the algorithm are designed to optimize the $\mathrm{CP}$ occurrences which coincide with extreme wave events. These are relatively rare events. A random classification leads to the same probability of occurrence as the mean for each rule, which is undesirable (Bárdossy, 2010). A good classification should lead to rules that differ from the climatological mean for the selected variable, in this case the wave height.

The intention of this classification is to find CPs that drive extreme wave events. Three objective functions were used as the performance measures. The first objective function relates to the conditional probability of an event based on the occurrence of a CP class. It is given as

$O_{1}(\theta)=\sqrt{\sum_{t=1}^{T} h_{\mathrm{CP}(t)}\left(p\left(H_{\mathrm{s}} \geq \theta \mid \mathrm{CP}(t)\right)-\bar{p}\right)^{2}}$,

where $\theta$ is a predefined threshold, $T$ is the total number of days, $h_{\mathrm{CP}(t)}$ is the frequency of the $\mathrm{CP}$ class, $p(\mathrm{CP}(t))$ is the probability that the threshold is exceeded for a given $\mathrm{CP}$ on a day $t$, and $\bar{p}$ is the unclassified probability of exceedance for all days in period $T$. The advantage of incorporating a predefined threshold $\theta$ is to allow the algorithm to evaluate different scenarios. For this study two different thresholds were considered. The first relates to extreme wave events where $\theta_{1}=3.5 \mathrm{~m}$. The second, with $\theta_{2}=2.5 \mathrm{~m}$, allows the algorithm to explore a larger data set for deriving the classes.

Another useful measure of performance relates to the mean significant wave heights. The ratio between the $\mathrm{CP}$ class-averaged wave heights to the unclassified mean provides information on the separability of the classes from the mean. Therefore the second objective function incorporating average significant wave heights is defined as

$O_{2}=\sum_{t=1}^{T} h_{\mathrm{CP}(t)}\left|\frac{H_{\mathrm{S}}(\mathrm{CP}(t))}{\overline{H_{\mathrm{S}}}}-1\right|$, 
where $H_{\mathrm{s}}(\mathrm{CP}(t))$ is the mean significant wave height on a day with the given $\mathrm{CP}(t)$ class and $\overline{H_{\mathrm{S}}}$ is the mean daily wave height without classification. Storm durations are defined as the times from when wave heights exceed $3.5 \mathrm{~m}$ to the time when they again reduce below $3.5 \mathrm{~m}$. To account for the persistence of types of CPs during extreme events, Eq. (5) was modified to include storm durations as

$O_{3}=\sum_{t=1}^{T} h_{\mathrm{CP}(t)}\left|\frac{D(\mathrm{CP}(t))}{\bar{D}}-1\right|$,

where $D(\mathrm{CP}(t))$ is the average storm duration for the $\mathrm{CP}(t)$ class and $\bar{D}$ is the unclassified average storm duration.

A weighted linear combination of Eqs. (4), (5) and (6) was used to optimize the solution to the classification algorithm. The weights were chosen to emphasize the importance of certain objective functions relative to others and to correct for the different magnitudes of the three objective functions.

\subsection{Classification quality}

Classification quality refers to the ability of the algorithm to maximize dissimilarity between a set of $\mathrm{CP}$ classes while minimizing variability within each $\mathrm{CP}$ class. This study focuses on classifying CPs driving extreme wave events. Therefore there are two criteria for measuring the classification quality. The first is the ability of the classification to explain extreme wave events. The second is the variability of the classifications within each CP class. There exists an optimal number of $\mathrm{CP}$ rules which successfully explain extreme events and daily $\mathrm{CP}$ realizations. Too few rules implies that the resulting CPs do not allow a proper distinction of the causal mechanisms and would lead to classes which have statistics similar to the unclassified case. Too many classes increases the computational effort and captures features that are not general and do not correspond to the wave generating mechanisms. Bárdossy (2010) suggests utilizing the objective functions as a measure of the classification quality. Huth et al. (2008) list a number of different quality measures that explain the separability between and variability within $\mathrm{CP}$ classes. For this study the variability within the classes as well as the degree of fit are used as measures of the classification quality. This provides insight into the performance of the classes with respect to their ability to explain average CPs.

The variability of extreme events is defined as the position of the lowest anomaly relative to the average pattern. This was assumed as the storm centre. Wave events are driven by storms associated with low pressures (i.e. negative anomalies). The performance of the CP classes in explaining extreme wave events can be measured by their relative contribution to extreme events, namely $p\left(\mathrm{CP} \mid H_{\mathrm{s}} \geq \theta\right)$, where $\theta$ is a predefined threshold (for this study $3.5 \mathrm{~m}$ ). A classification strongly linked to the wave climate should define classes whose frequency of occurrence corresponds to the average and extreme wave events. This implies that CPs driving extreme events should occur infrequently, whereas CPs driving the average wave climate should occur more frequently.

\section{Results}

\subsection{Dominant CP classes}

The objective functions (Eqs. 4, 5 and 6) were used to derive a set of $\mathrm{CP}$ classes which explain extreme wave events. Figure 2 shows the average anomaly patterns for all the $\mathrm{CP}$ classes. CP99 refers to an unclassified class. Useful statistical parameters relevant to this study for a given CP class are (a) frequency of occurrence, (b) percentage contribution of extreme events, and (c) average and maximum significant wave heights $\left(\bar{H}_{\mathrm{s}}\right)$. These parameters are obtained from the classification and are shown in Table 2.

The results show two trends in CPs that drive wave development. Firstly CP01 and CP02 (Fig. 2a and b) according to Table 2 occur most frequently ( $\sim 17 \%$ of the time). CP01 resembles that of mid-latitude cyclones which frequently travel in a west to east direction south of the country, while $\mathrm{CP} 02$ resembles the high-pressure systems that follow the midlatitude cyclones. Secondly, Table 2 shows that $\mathrm{CP} 03$ is associated with $30-60 \%$ of all extreme wave events. The large contribution by this class to extreme events is present all year-round with the highest contribution in winter $(\sim 65 \%)$. CP03 (Fig. 2c) occurs infrequently (7-9\% of the time), but when it does occur it is associated with average and maximum significant wave heights ranging from 2.4 to 3.0 and from 5.0 to $8.5 \mathrm{~m}$, respectively. CP05 and CP06 (Fig. 2e and $\mathrm{f}$ ) according to the classification are responsible for about $30 \%$ of extreme events in spring and summer, respectively. CP06 represents low-pressure anomalies southeast of Madagascar. This appears to resemble the strong low-pressure systems that are associated with tropical cyclones. According to Mather and Stretch (2012) low-pressure systems southeast of Madagascar can cause large swells. CP05 resembles lowpressure systems over the interior which extend southwards.

No time lag was considered when deriving the CP classes. This constrains the algorithm to only consider CPs occurring on the day of a wave event and assumes that extreme events are driven by relatively stationary CPs.

\subsection{CP variability}

\subsubsection{Degree of fit (DOF)}

The degree of fit relates to how well the $\mathrm{CP}$ for each day is classified as a given class relative to the rule file. The larger the degree of fit is, the stronger the relation between the $\mathrm{CP}$ and the $\mathrm{CP}$ class. Figure 4 shows the average anomaly pattern for $\mathrm{CP} 03$ together with the CPs associated with both the highest and lowest degree of fit value for that class. CP03 is associated with cut-off lows to the east/south-east of South 


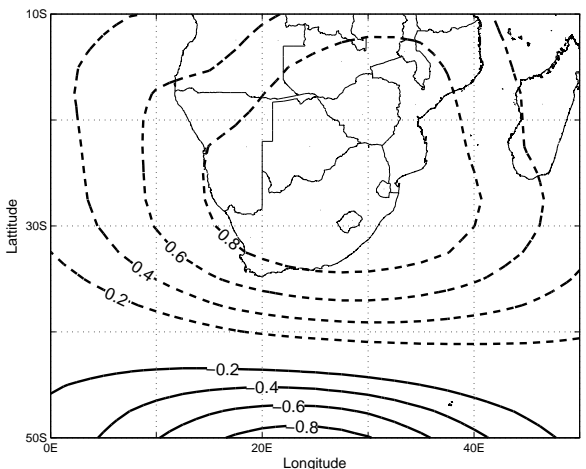

(a) $\mathrm{CP} 01$

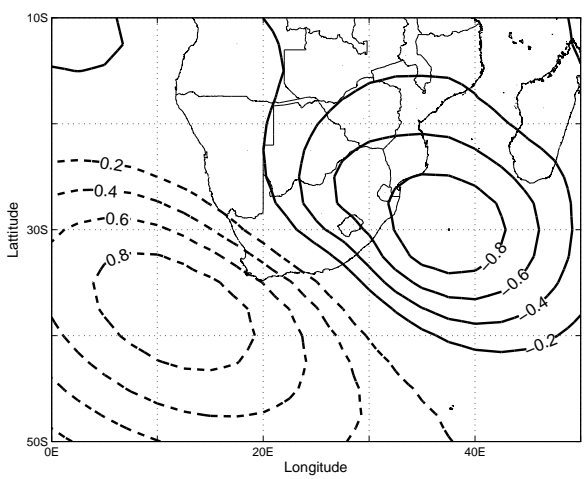

(c) $\mathrm{CP} 03$

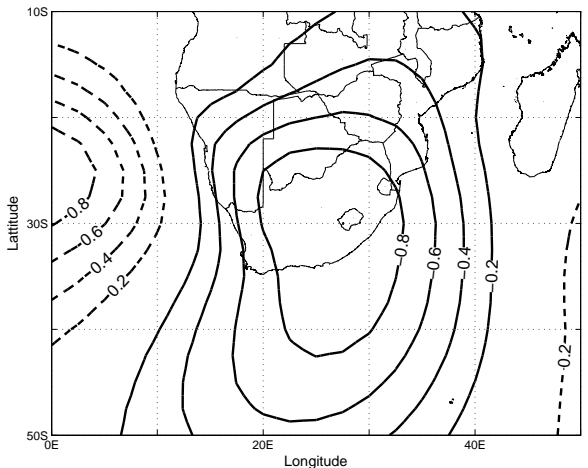

(e) $\mathrm{CP} 05$

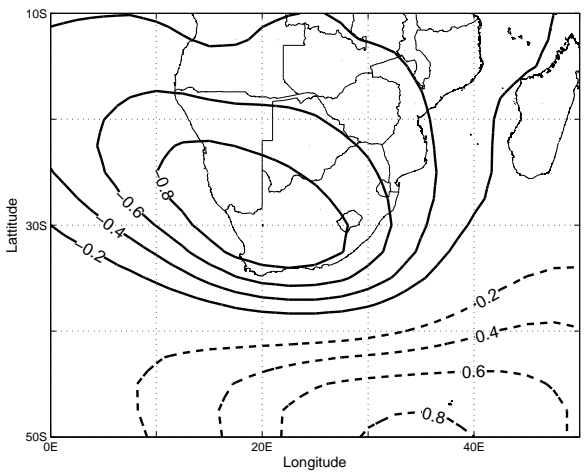

(g) CP07

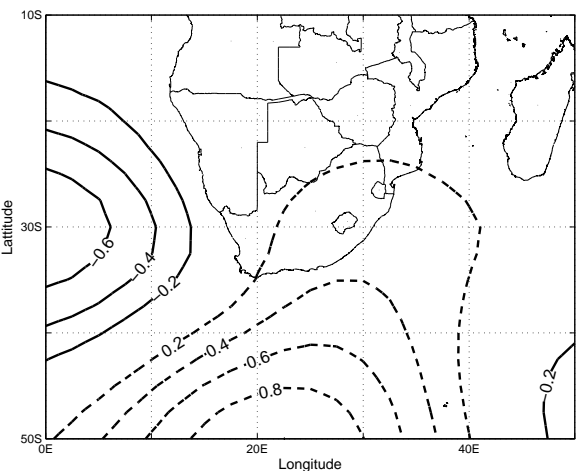

(b) $\mathrm{CP} 02$

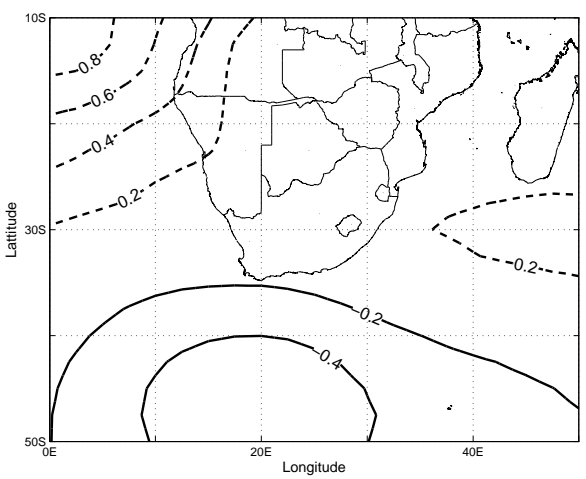

(d) $\mathrm{CP} 04$

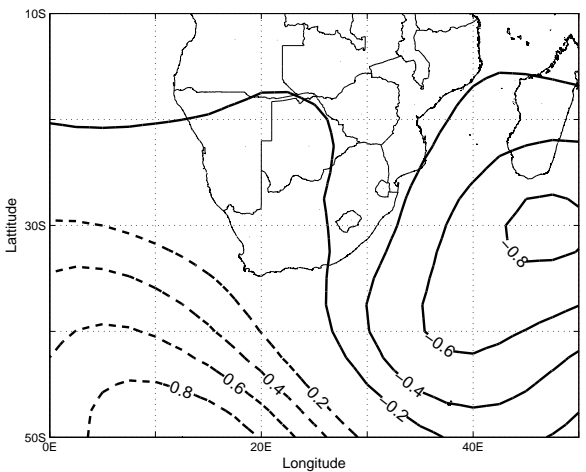

(f) $\mathrm{CP} 06$

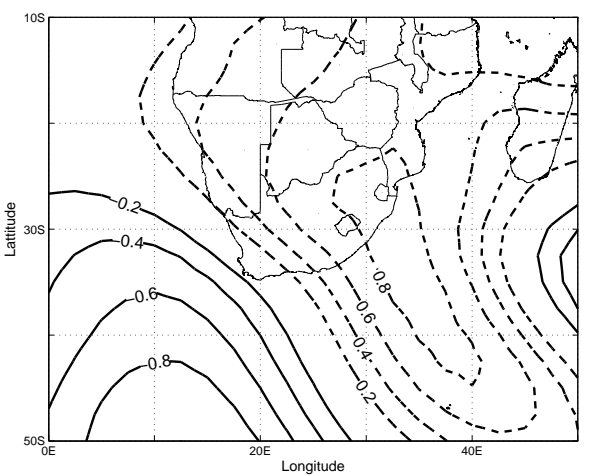

(h) CP08

Figure 2. Average anomaly patterns for all CP classes: 1-8. Positive anomaly contours are shown as the dashed line while negative contours are solid. 
Table 2. CP occurrence frequencies and wave height statistics associated with each CP. Statistics were calculated for the period 1992-2009.

\begin{tabular}{|c|c|c|c|c|c|c|c|c|c|}
\hline Statistics & CP01 & $\mathrm{CP} 02$ & CP03 & CP04 & CP05 & CP06 & СР07 & CP08 & CP99* \\
\hline \multicolumn{10}{|c|}{ Occurrence frequency $(p(\mathrm{CP}) \%)$} \\
\hline Summer & 18 & 18 & 8.0 & 13 & 7.5 & 8.1 & 5.6 & 15 & 8.3 \\
\hline Autumn & 18 & 19 & 8.0 & 11 & 10 & 7.2 & 5.1 & 13 & 8.8 \\
\hline Winter & 16 & 17 & 8.1 & 12 & 11 & 8.4 & 4.5 & 14 & 8.9 \\
\hline Spring & 17 & 16 & 9.1 & 12 & 9.4 & 7.7 & 5.0 & 15 & 9.2 \\
\hline All seasons & 17 & 17 & 8.3 & 12 & 9.6 & 7.8 & 5.1 & 14 & 8.8 \\
\hline \multicolumn{10}{|c|}{ Threshold exceedance for a given $\mathrm{CP}\left(p\left(H_{\mathrm{S}} \geq \theta \mid \mathrm{CP}\right) \%\right)$} \\
\hline Summer & - & 0.4 & 8.0 & 0.3 & - & 3.5 & 2.6 & 0.7 & - \\
\hline Autumn & 1.2 & 1.5 & 12 & 1.6 & 2.1 & 2.0 & 5.6 & 0.6 & 5.0 \\
\hline Winter & 0.9 & 0.8 & 14 & - & 0.9 & 0.4 & 2.3 & 0.8 & 0.4 \\
\hline Spring & 0.3 & - & 4.6 & 0.6 & 2.2 & - & 0.7 & - & - \\
\hline All seasons & 0.6 & 0.7 & 9.6 & 0.6 & 1.4 & 1.5 & 2.8 & 0.5 & 1.4 \\
\hline
\end{tabular}

\begin{tabular}{|c|c|c|c|c|c|c|c|c|c|}
\hline \multicolumn{10}{|c|}{ Exceedance contribution $\left(p\left(\mathrm{CP} \mid H_{\mathrm{S}} \geq \theta\right) \%\right)$} \\
\hline Summer & - & 5.6 & 50 & 2.8 & - & 22 & 11 & 8.3 & - \\
\hline Autumn & 7.7 & 10 & 33 & 6.4 & 7.7 & 5.1 & 10 & 2.6 & 17 \\
\hline Winter & 7.5 & 7.5 & 64 & - & 5.7 & 1.9 & 5.7 & 5.7 & 1.9 \\
\hline Spring & 4.5 & - & 55 & 9.1 & 27 & - & 4.5 & - & - \\
\hline All seasons & 5.8 & 7.4 & 48 & 4.2 & 7.9 & 6.9 & 8.5 & 4.2 & 7.4 \\
\hline \multicolumn{10}{|c|}{ Average $H_{\mathrm{S}}(\mathrm{m})$ for each $\mathrm{CP}$} \\
\hline Summer & 1.8 & 1.9 & 2.5 & 1.8 & 1.8 & 2.2 & 2.2 & 1.9 & 1.9 \\
\hline Autumn & 1.8 & 1.9 & 2.7 & 1.9 & 2.0 & 2.0 & 2.1 & 1.9 & 2.1 \\
\hline Winter & 2.0 & 2.0 & 2.9 & 1.9 & 2.1 & 2.0 & 2.2 & 2.0 & 1.9 \\
\hline Spring & 2.0 & 1.9 & 2.4 & 1.9 & 2.2 & 2.0 & 2.2 & 2.0 & 2.0 \\
\hline All seasons & 1.9 & 1.9 & 2.6 & 1.9 & 2.1 & 2.1 & 2.2 & 2.0 & 2.0 \\
\hline \multicolumn{10}{|c|}{ Standard deviation of $H_{\mathrm{S}}(\mathrm{m})$ for each $\mathrm{CP}$} \\
\hline Summer & 0.48 & 0.49 & 1.1 & 0.49 & 0.53 & 0.76 & 0.74 & 0.61 & 0.49 \\
\hline Autumn & 0.58 & 0.66 & 1.0 & 0.70 & 0.76 & 0.66 & 0.90 & 0.55 & 1.0 \\
\hline Winter & 0.58 & 0.61 & 0.94 & 0.55 & 0.66 & 0.58 & 0.66 & 0.55 & 0.67 \\
\hline Spring & 0.51 & 0.49 & 0.84 & 0.52 & 0.71 & 0.50 & 0.61 & 0.50 & 0.49 \\
\hline All seasons & 0.54 & 0.57 & 1.0 & 0.56 & 0.69 & 0.63 & 0.74 & 0.56 & 0.70 \\
\hline \multicolumn{10}{|c|}{$\operatorname{Max} H_{\mathrm{S}}(\mathrm{m})$ for each CP } \\
\hline Summer & 3.4 & 4.0 & 8.5 & 3.7 & 3.4 & 5.0 & 5.2 & 5.6 & 3.3 \\
\hline Autumn & 4.0 & 5.5 & 5.7 & 5.5 & 6.3 & 4.3 & 5.1 & 4.0 & 5.4 \\
\hline Winter & 4.2 & 3.8 & 5.6 & 3.4 & 3.8 & 3.5 & 4.3 & 4.8 & 3.6 \\
\hline Spring & 3.9 & 3.3 & 5.3 & 4.5 & 5.4 & 3.4 & 3.7 & 3.5 & 3.3 \\
\hline All seasons & 4.2 & 5.5 & 8.5 & 5.5 & 6.3 & 5.0 & 5.2 & 5.6 & 5.4 \\
\hline
\end{tabular}

* CP99 is the unclassified class. Blank entries imply zero occurrences in the data set.

Africa. The pattern also shows a strong high-pressure region to the southwest. The combination of strong cut-off lows occurring in conjunction with high-pressure regions comprises an important feature for channelling waves towards the eastern coastline. Figure $4 \mathrm{c}$ is the $\mathrm{CP}$ with the lowest degree of fit for the class $\mathrm{CP} 03$, and it shows only a weak anomaly pattern.

\subsubsection{Variability within classes}

It is expected that in the vicinity of the regions defining rule types (high or low pressures) the standard deviation should be low. This is because the classification is based on the location of these rules in comparison to the anomaly patterns for specific days. Whereas the locations of "any anomaly" rule types (fuzzy number 0) are expected to have significant variability, the variability in the vicinity of negative anomalies 


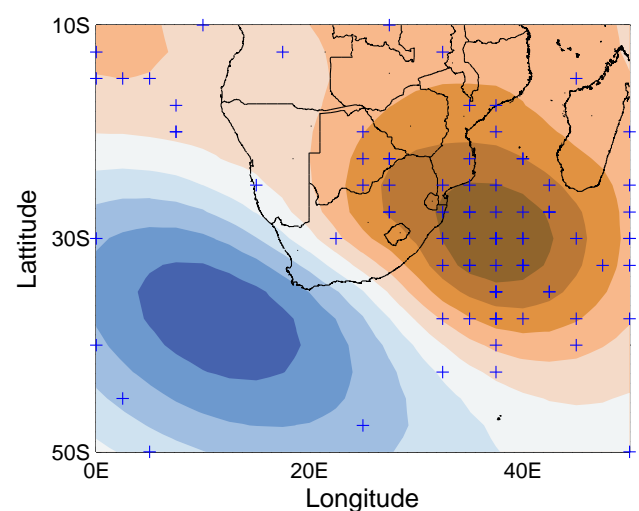

(a)
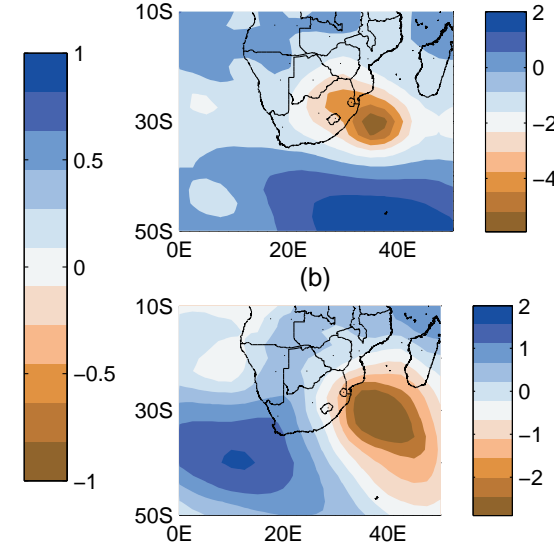

(c)

Figure 3. (a) Average $\mathrm{CP} 03$ with (+) symbols indicating the centres of all negative anomalies (low pressures) contributing to the class during extreme events. (b) and (c) show actual CPs for the dates 19 March 2007 and 30 August 2006, respectively, both of which were classified as members of the CP03 class.

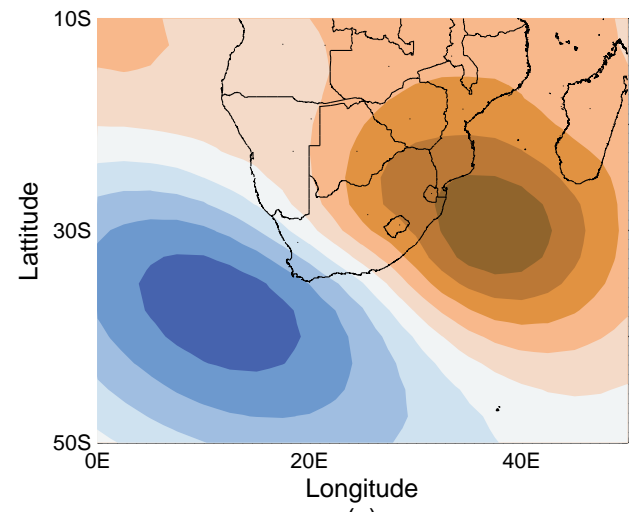

(a)
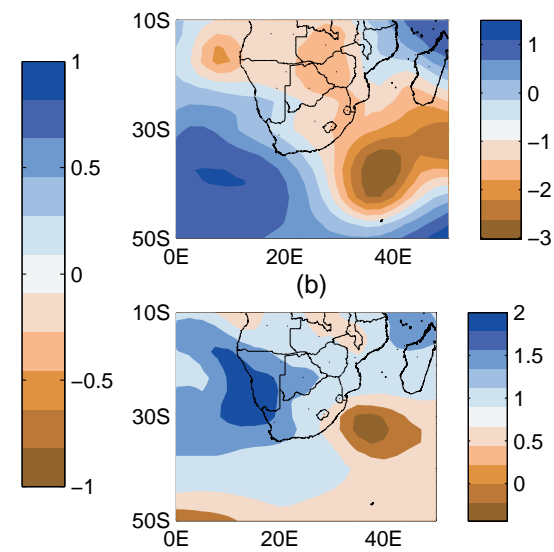

(c)

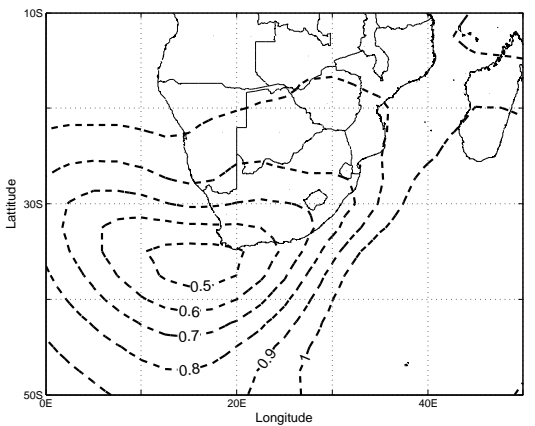

(d)

Figure 4. Average anomaly pattern for $\mathrm{CP} 03$ (a) with (b) the anomaly with highest DOF, (c) the anomaly with lowest DOF value, while (d) shows the standard deviation for all CP03 anomalies.

(low pressures) can be attributed to the movement of the lowpressure systems. It is also expected that high-pressure systems are more stable with lower variability in their positions. For example Fig. 4d shows lower variability in the vicinity of the high-pressure region while high variability (standard deviation of (1) in the low-pressure region. This can be attributed to the movement of low-pressure systems around the negative anomaly. Figure 4d shows high standard deviation values in comparison to the mean negative anomaly. This 
could also indicate that $\mathrm{CP}$ anomalies driving extreme events (cut-off lows) are associated with strong negative anomalies.

\subsection{CP rules and extreme events}

Daily CPs classified as in a certain class for extreme wave events $\left(H_{\mathrm{s}} \geq 3.5 \mathrm{~m}\right)$ were compared to the average patterns for that class. Figure 3 shows the average pattern for $\mathrm{CP} 03$ together with selected extreme events corresponding to $\mathrm{CP} 03$. The centres of the CPs are shown as "+" symbols in the plot. A centre is defined as the location of the peak negative anomaly. The variability within the class is apparent. However the majority of CPs classified as CP03 resemble strong cut-off lows to the east/southeast of the country. It is apparent that these strong cut-off lows drive extreme wave events. Figure 5 and Table 3 show CPs associated with the six largest significant wave height events. Four out the six events have been classified as $\mathrm{CP} 03$, the class contributing to the majority of extreme events. The concept of CPs belonging, to some degree, to all the classes is evident in Fig. 5f. This shows a similar pattern to CP04 and CP08, which both represent low pressures southeast of Madagascar. However according to the classification this CP belongs to class CP08 and not CP04. From visual inspection it appears to resemble class $\mathrm{CP} 04$ better than $\mathrm{CP} 08$. Figure $5 \mathrm{a}$ and $\mathrm{c}$ are the CPs associated with the March 2007 storm which caused severe coastal erosion along the KwaZulu-Natal coastline (Mather and Stretch, 2012; Corbella and Stretch, 2012a) with significant wave heights reaching $8.5 \mathrm{~m}$.

\section{Discussion}

Classifying circulation patterns is a useful tool for investigating the occurrence of certain patterns over a given region. There are many different techniques used for classifying CPs, each of which has its benefits and drawbacks (Huth et al., 2008). Classification can be subjective or objective (to a degree). However the goal is always to group similar patterns into individual classes. A useful application for engineering purposes is utilizing a variable of interest to "guide" the algorithm to find CPs linked to its occurrence. Bárdossy et al. (2002) successfully implemented this to classify CPs that explained wet and dry events in Europe.

The emphasis of the present study has been on the statistical link between atmospheric circulation patterns and extreme wave events. This is the first time the method described here has been used in this context, and it has the potential to improve current methods of risk analysis. The benefit of fuzzy logic as a classification tool is that each daily $\mathrm{CP}$ belongs, to some degree, to all the $\mathrm{CP}$ classes. This is characteristic of atmospheric circulation where daily CPs form part of a continuum rather than a set of individual states as suggested by the derived CP classes (Huth et al., 2008). However a potential drawback of the method is the manner in which the
Table 3. Six of the most extreme wave events on record and their associated CPs for the period 1992 to 2009.

\begin{tabular}{llcc}
\hline Fig. 5 & Date & $\mathrm{CP}$ & $H_{\mathrm{S}}(\mathrm{m})$ \\
\hline (a) & 19 Mar 2007 & CP03 & 8.50 \\
(b) & 5 May 2001 & CP05 & 6.30 \\
(c) & 18 Mar 2001 & CP03 & 5.92 \\
(d) & 3 Apr 2001 & CP03 & 5.66 \\
(e) & 23 Sep 1993 & CP03 & 5.64 \\
(f) & 19 Mar 2001 & CP08 & 5.63 \\
\hline
\end{tabular}

CPs on each day are assigned to a class (Huth et al., 2008). The degree of fit (Sect. 3) used in this study incorporates the connectivity to a given class through and/or combinations of high/low and not high/not low anomalies as described in Bárdossy et al. (1995). However this technique has been successful in associating CPs with rainfall events (e.g. Bárdossy et al., 2002; Bárdossy, 2010)

In the context of our case study site on the east coast of South Africa, the most frequent CPs are low- and highpressure anomalies located south of the country. This can be attributed to the west-east progression of mid-latitude cyclones which frequent this area. They are major contributors to the wave climate along the South African coastline (Rossouw et al., 2011). The low-pressure systems can become isolated after being displaced towards the Equator and can become stationary (Preston-Whyte and Tyson, 1988). These stationary cut-off lows can drive the development of extreme wave events. Table 2 indicates that the dominant CP that drives extreme events along the KwaZuluNatal coastline is $\mathrm{CP} 03$, which is associated with abnormally low pressure to the east-southeast. CPs classified as CP03 resemble cut-off lows, and the pattern agrees with speculations by Mather and Stretch (2012), Rossouw et al. (2011) and Corbella and Stretch (2012b) concerning drivers of extreme waves. Low-pressure anomalies linked to storms east to south-east of South Africa drive wind fields that direct the wave attack toward the coastline.

Callaghan et al. (2008) and Corbella and Stretch (2013) highlight the importance of identifying independent storms for risk analysis of extreme wave events. One limitation with the methods described herein is that it is difficult to evaluate the independence of the different CPs. A particular storm in various stages of development may belong to a number of $\mathrm{CP}$ classes rather than a single class according to the classification scheme. Examples are cut-off lows that become detached from extratropical cyclones travelling west to east in the region south of the country. The process of storm development drives wave development. This suggests that it may be better to locate a specific type of $\mathrm{CP}$ at any location rather than a specified type of $\mathrm{CP}$ at a fixed location. 


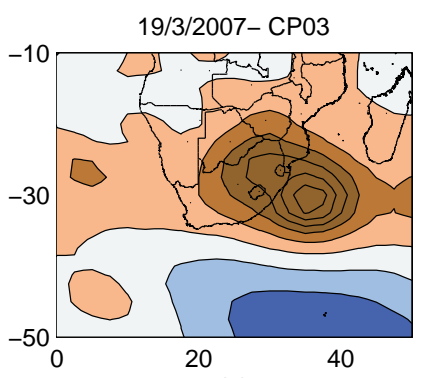

(a)

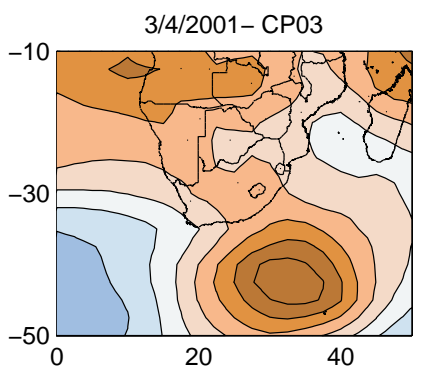

(d)

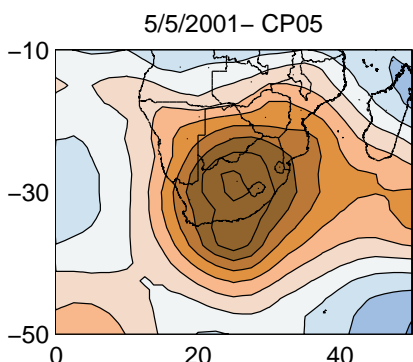

(b)

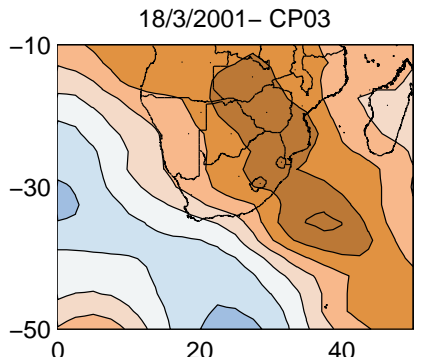

(c)

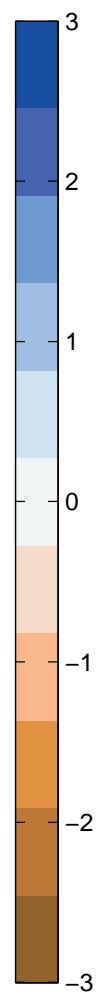

Figure 5. CPs associated with the six largest significant wave heights for the dates (a) 19 March 2007, (b) 5 May 2001, (c) 18 March 2001, (d) 3 April 2001, (e) 23 September 1993 and (f) 19 March 2001.

\section{Conclusions}

A fuzzy-rule-based classification method has been adapted to identify the atmospheric circulation patterns that drive regional wave climates. The east coast of South Africa was used as a case study. The method is based on normalized anomalies in daily $700 \mathrm{hPa}$ geopotential heights. The $\mathrm{CP}$ classes are derived from an optimization procedure which is guided by a variable of interest, in this case wave heights. The classification shows a strong anomaly pattern east-southeast of South Africa which explains 30-60\% of extreme wave events. This CP type explains extreme events in all seasons. However it occurs infrequently ( $\sim 8 \%$ of the time) and is associated with large wave heights ranging from 5.0 to $8.5 \mathrm{~m}$. Frequently occurring $\mathrm{CP}$ classes have a similar structure to mid-latitude cyclones or translational low-pressure systems (followed by a zone of high pressure) that occur south of South Africa (Taljaard, 1967).

The methodology discussed here appears to be new in the context of wave climate analysis and has potential for application to risk assessment studies in coastal management and engineering.
Acknowledgements. Wave data for the study were provided by eThekwini Municipality, Council for Scientific and Industrial Research, and the SA National Port Authority. The ERA-Interim data were provided by ECMWF. We are grateful for funding from the eThekwini Municipality, the National Research Foundation, and the Nelson Endowment Fund in the UKZN School of Engineering.

Edited by: R. Lasaponara

Reviewed by: three anonymous referees

\section{References}

Aarts, E. and Korst, J.: Simulated annealing and Boltzmann machines: a stochastic approach to combinatorial optimization and neural computing, John Wiley \& Sons, Chichester, 1989.

Bárdossy, A.: Atmospheric circulation pattern classification for South-West Germany using hydrological variables, Phys. Chem. Earth, 35, 498-506, 2010.

Bárdossy, A., Duckstein, L., and Bogardi, I.: Fuzzy rule-based classification of atmospheric circulation patterns, Int. J. Climatol., 15, 1087-1097, 1995.

Bárdossy, A., Stehlik, J., and Caspary, H. J.: Automated objective classification of daily circulation patterns for precipitation and temperature downscaling based on optimized fuzzy rules, Clim. Res., 23, 11-22, 2002.

Callaghan, D. P., Nielson, P., Short, A., and Ranasinghe, R.: Statistical simulation of wave climate and extreme beach erosion, Coast. Eng., 55, 375-390, 2008. 
Corbella, S. and Stretch, D. D.: Shoreline recovery from storms on the east coast of Southern Africa, Nat. Hazards Earth Syst. Sci., 12, 11-22, doi:10.5194/nhess-12-11-2012, 2012a.

Corbella, S. and Stretch, D. D.: The wave climate on the the KwaZulu Natal Coast, J. S. Afr. Inst. Civ. Eng., 54, 45-54, 2012b.

Corbella, S. and Stretch, D. D.: Simulating a multivariate sea storm using Archimedean copulas, Coast. Eng., 76, 68-78, 2013.

Hess, P. and Brezowsky, H.: Katalog der Großwetterlagen Europas, Ber. DT. Wetterd. in der US-Zone 33, Bad Kissingen, Germany, 1952.

Hewitson, B. and Crane, R.: Self-organizing maps: applications to synoptic climatology, Clim. Res., 22, 13-26, 2002.

Huth, R., Beck, C., Philipp, A., Demuzere, M., Ustrnul, Z., Cahynová, M., Kyselý, J., and Tveito, O. E.: Classifications of atmospheric circulation patterns: recent advances and application, Ann. New York Acad. Sci., 1146, 105-152, 2008.

Komar, P. D., Allan, J. C., and Ruggiero, P.: Ocean Wave Climates: Trends Variations Due to Earth's Changing Climate, in: Handbook of coastal and ocean engineering, edited by: Kim, Y., chap. 35, World Scientific Publishing Co., Hackensack, USA, 972-995, 2010.
Lamb, H. H.: British Isles weather types and a register of the daily sequence of circulation patterns, 1861-1971, Geophysical Memoir No. 116, Meteorological Office, HMSO, London, 1972.

Mather, A. A. and Stretch, D. D.: A perspective on sea level rise and coastal storm surge from southern and eastern Africa: a case study near Durban, South Africa, Water, 4, 237-259, 2012.

Preston-Whyte, R. A. and Tyson, P. D.: The atmosphere and weather of Southern Africa, Oxford University Press, Cape Town, 1988.

Rossouw, J., Coetzee, L., and Visser, C.: A South African wave climate study, Coastal Engineering Proceedings, 18, https:// journals.tdl.org/icce/index.php/icce/article/view/3618/3300 (last access: August 2013), 2011.

Taljaard, J.: Development, Distribution and Movement of Cyclones and AntiCyclones in the South Hemishpere During the IGY, J. Appl. Meteorol., 6, 973-987, 1967.

Zadeh, L.: Fuzzy Sets, Information Control, 8, 338-353, 1965. 